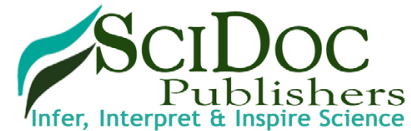

International Journal of Natural Disasters \& Health Security (IJNHS)

ISSN 2572-7540

\title{
Food Security and Household Coping Strategies During Disasters in Bangladesh
}

Research Article

Alam E*

Associate Professor, Department of Geography and Environmental Studies, University of Chittagong, Chittagong, Bangladesh.

\section{Abstract}

Bangladesh is currently ranked as one of the world's most disaster prone countries. Approximately ninety seven percent of the total land area and all inhabitants are at risk of multiple hazards including tropical cyclones, earthquakes, floods, droughts, riverbank and coastal erosion. Food security is a challenge when a disaster heavily affects an area. The main aim of this research is to analyse how households themselves attempted to cope for food during major disaster events in Bangladesh. To achieve the objectives of this research, data on disasters and coping strategies for food were collected from the Government of Bangladesh and NGO's publications, local histories, journal articles in the peer reviewed literature, books, newspapers, magazines, annual reports and online hazard databases. The findings suggest that affected household undertook several food coping strategies through their available resources and traditional social networks following disaster events. It was noted that coping strategies depend on types, severity and time of disaster and socio-demographic characteristics of the affected households. Generally the poor, agricultural and fishing communities whose livelihood depends are located in hazardous locations are found to adopt least preferable coping strategies for food during and following disaster occurrence. Household resilient for food security could be improved through providing access to food for all class of people and undertaking preparedness and increasing household level capacity building programme.

Keywords: Household; Food Security; Disasters; Coping and Adaptation.

\section{Introduction}

Natural hazards challenge food security in the short term with food shortages and in the long term the development of economy. Distuption of food security is often seen during times of natural disasters [9]. International attention to the concept of food security can be traced back to the Universal Declaration of $\mathrm{Hu}-$ man Rights in 1948, which recognized the right to food as a core element of an adequate standard of living [33]. Bangladesh is currently ranked as one of the world's most disaster prone countries with almost all population at risk of multiple hazards [39]. A disaster may be defined as a serious disruption of the functioning of a community or a society involving widespread human, material, economic or environmental losses and impacts, which exceeds the ability of the affected community or society to cope using its own resources [35]. In the United Nations General Assembly on 6 to 7 September 2000, at the dawn of a new millennium declared millennium development goals for world community. Of the eight point Millennium Development Goals (MDGs) declared in 2000, the first one is eradicating extreme poverty and hunger [34]. On the other hand, the adoption of the Hugo framework for Action 2005-2015 and Sendai Framework for Action 2015-2030 is a positive move to foster a culture of prevention and resilience building in disasters [35]. In this regard, the Ministry of Food and Disaster Management of Bangladesh [23] current mission is to bring a paradigm shift in disaster management from conventional response and relief to a more comprehensive risk reduction culture and to promote food security as an important factor in ensuring the resilience of communities to hazards [23]. Failure of any food to be accessible leads to epidemic under nutrition (famine). Famine may also occur on a larger and longer scale when environmental condition change or become significantly unstable [28]. Based on the rationale above, the aim of this research is to understand how households themselves attempted to cope for food during major disaster events in Bangladesh.

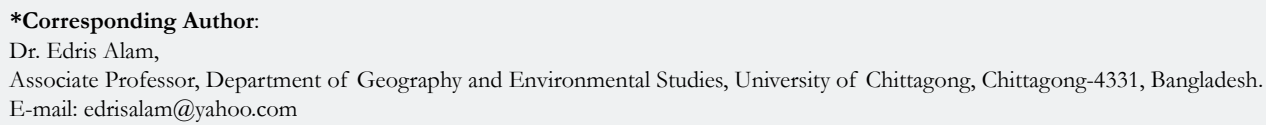

Citation: Alam E (2017) Food Security and Household Coping Strategies During Disasters in Bangladesh. Int J Natural Disaster Health Secur. 4(1), 30-35. doi: http://dx.doi.org/10.19070/2572-7540-170006

Copyright: Alam $\mathbf{E}^{\circ}$ 2017. This is an open-access article distributed under the terms of the Creative Commons Attribution License, which permits unrestricted use, distribution and reproduction in any medium, provided the original author and source are credited. 


\section{Food Security}

The concept of food security is multi-dimensional and provides valuable insights into the nature and extent of population's food situation. Additionally, food security can be looked at from many different levels: global, national, local and family. However, it is about individuals. A food-secure household can be defined as one which has enough food available to ensure a minimum necessary intake by all members [1]. The United Nations subcommittee on nutrition defines household food security as the ability of household members to ensure themselves sustained access to sufficient quantity and quality of food to live health active lives both at present and in future [32]. Household food security has three main components: availability, access, and usage and these three pillars of food security can be shocked by a variety of risk factors including natural disasters, conflicts and policy changes [36]. The concept of livelihoods broadens the traditional understanding of food security. In a livelihood system, the goal is to procure all the capabilities, assets and activities required for a means of living. Food availability could be disrupted by natural disasters [36].

\section{Household Coping Strategies in Disasters}

Coping is the manner in which people act within the limits of existing resources and range of expectations to achieve various ends. In general, this involves no more than managing resources, but it means how it is done unusual, abnormal and adverse situations. Thus, coping can include defence mechanisms, active ways of solving problems and methods for handling stress. Hewitt [16] defined this as Coping refers to the actions of ordinary people or disrupted remains of institutions, in contrast to official and planned response. Coping strategies are employed to satisfy human need of food during any sort of crisis period [36]. For this research, household coping may be loosely defined endeavour of household members to get food items and intervention of relatives, neighbours and social networks for achieving minimum survival of food in a disaster period.

\section{Methods and Materials}

This research was conducted based on documentary and online database on food security and household coping strategies during disasters of Bangladesh. The documentary sources include archives of institutional and administrative memories, the Government of Bangladesh and NGOs publications, local histories, journal 4 articles in the peer reviewed literature, books, newspapers, magazines, annual reports, online hazard databases and chronicles. Data collected from local, regional, national and international sources. In order to understand food security and household coping strategies relevant theoretical literature were collated and analysed. Background of disasters in Bangladesh has been prepared consulting documents by extensive web searching, reading of books and research papers.

Disasters for this research have been considered famine, flood, cyclone, drought and tornado those are responsible for major losses and casualties in Bangladesh [10]. In order to analyse secondary data sources, this research applied content analysis. Content analysis may be defined as a set of methods for analyzing the symbolic content of any written communication. The basic idea is to reduce the total content of a communication to a set of categories that represent some characteristic of research interest [31]. Content analysis has traditionally been used to analyse novels, newspapers, and other media in order to characterize and evaluate the message being conveyed by them or the apparent assumptions or attitudes contained within them. This research has extensively used content analysis in order to understand food security in disaster period and household level coping strategies, to verify inconsistencies within data and to validate their sources.

\section{Result}

\section{Famine-1974 in Bangladesh and entitlement approach}

The availability of food is a significant resilient parameter during and following disaster event to cope with disastrous situation. The 1974 flood event caused severe damage in the northern districts of Bangladesh. In normal years, the Brahmaputra encroaches on its western bank 30-60m during peak floods. In 1974, over a distance of $100 \mathrm{~km}$., it flooded land on a strip $300 \mathrm{~m}$ wide in areas having a density of 900 per sq. km. [13]. The CRED (Centre for Research in the Epidemiology of Disasters (CRED)) estimated the total number of flood casualties by the flood event were 24700 [10]. The government of Bangladesh officially declared famine in late September. Some langarkhanas, providing modest amounts of free cooked food to destitute, were opened under private initiative early in September, and government-sponsored langarkhanas went into full operation in early October.

Altogether six thousand langarkhanas supplied cooked food relief to 4.35 million people, more than 6 percent of the total population of the country. By November rice prices were beginning to come down and the need for relief seemed less intense. By the end of the month the langarkhanas were closed down [29]. The reasons of food crisis in disasters may depend on unseen factors and do not always mean the shortage of food in declared hazardous areas.

Sen (1982) [29] used entitlement approach to understand poverty and more specially famine where the cases of the great Bengal famine-1943 and Bangladesh famine-1974 were highlighted. In line with this research, Sen's [29] entitlement approach can be applied. Sen (1982) [29] showed that though per capita rice output (Table 1) and food grains availability (Table 2) did not decline during flood-1974, the preceding and the following flood year. Despite a better food production and availability of food, the worst famine of the world has taken place in Bangladesh. The reasons for the famine were not the shortage of food, it were likely due to improper distribution and access to food by all classes of people [29].

\section{Household coping strategies for food during 1998 flooding events}

Flooding may affect the nutritional status of the population, and nutritional status is a critical determinant of health outcomes. Although Bangladesh is self-sufficient in grain production during normal time, the flood disaster has the potential to disrupt food production and distribution, damage existing stores and limit employment and income [24]. Large scale flooding in Bangladesh is thought to put an affected population that has already faced marginal food security and poor nutritional status at a very high 
Table 1: Rice output of Bangladesh, 1971-5. Source: [29]

\begin{tabular}{|c|c|c|c|c|}
\hline Year & $\begin{array}{c}\text { Production of } \\
\text { Rice (thousand } \\
\text { tons) }\end{array}$ & $\begin{array}{c}\text { Index of rice } \\
\text { production }\end{array}$ & $\begin{array}{c}\text { Per Capita Rice } \\
\text { Output (tons.) }\end{array}$ & $\begin{array}{c}\text { Index of per } \\
\text { capita rice } \\
\text { output }\end{array}$ \\
\hline 1971 & 10,445 & 100 & 0.133 & 100 \\
\hline 1972 & 9,706 & 93 & 0.120 & 90 \\
\hline 1973 & 10,459 & 100 & 0.126 & 95 \\
\hline 1974 & 11,778 & 113 & 0.139 & 105 \\
\hline 1975 & 11,480 & 110 & 0.132 & 99 \\
\hline
\end{tabular}

Table 2. Food Grains Availability in Bangladesh, 1971-5. Source: [29].

\begin{tabular}{|c|c|c|c|c|}
\hline Year & $\begin{array}{c}\text { Total available } \\
\text { food grains for } \\
\text { consumption } \\
\text { (Million tons) }\end{array}$ & $\begin{array}{c}\text { Population } \\
\text { (Millions) }\end{array}$ & $\begin{array}{c}\text { Per capita } \\
\text { availability } \\
\text { (oz./day) }\end{array}$ & $\begin{array}{c}\text { Index of Per } \\
\text { Capita } \\
\text { availability }\end{array}$ \\
\hline 1971 & 10.740 & 70.679 & 14.9 & 100 \\
\hline 1972 & 11.271 & 72.535 & 15.3 & 103 \\
\hline 1973 & 11.572 & 74.441 & 15.3 & 103 \\
\hline 1974 & 12.355 & 76.398 & 15.9 & 107 \\
\hline 1975 & 12.022 & 78.405 & 14.9 & 100 \\
\hline
\end{tabular}

risk of severe food shortages and resultant malnutrition [21]. For example, the 1998 flood in Bangladesh led to major crop losses, losses of other assets and lower employment opportunities and subsequently this affected household incomes as well as market prices. Ninno et al., (2003) [11] analysed household level impacts and coping strategies in flood 1998, using data from a panel data set of 757 rural households collected in November/December 1998 (about three months after the flood), April/May 1999 and November/December 1999. Households exposed to the flood suffered severe crop losses (equal to $24 \%$ of the total value of anticipated production for the year). Households adjusted to the shock of the flood in several ways: reducing expenditures, selling assets and borrowing. Borrowing to purchase food and to fund other expenses has been the most important coping strategy employed by households in Bangladesh after the flood both in terms of the value of the resources and the number of households who borrowed. More than $60 \%$ of poor, flood-exposed households in the sample borrowed money in the months immediately following the flood, and of these more than half borrowed money for food [11]. Households borrowed mostly from non institutional sources such as friends and neighbours rather than from Non governmental Organizations (NGOs) and banks [11].

\section{Household coping strategies for food during the April 1991 tropical cyclone}

Tropical cyclones devastate large areas, take numerous lives and damage extensive property in Bangladesh [7, 8]. Varying types of community level food coping strategies were observed based on different height of storm surge following the April 1991 tropical cyclone in Bangladesh coast. Alam $(2002,2003)$ [3, 4] divided the Island of Sandwip, Bangladesh into three zones namely Badly Affected Area (BAA), Moderately Affected Area (MAA) and Less Affected Area (LAA) depending on the height of storm surge of the April 1991 tropical cyclone. The first seven days follow- ing the cyclone event was very crucial time for the survivors, but they remained without Governmental Organizations (GOs) and (NGOs) help [4]. In BAA, only two housewives cooked food after the day of tropical cyclone. The same was 27 out of 70 in MAA and 39 of 50 in LAA. In MAA, the most of residents starved for 3-4 days. For example, Anwara Khatun a resident in the BAA did not able to cook for 20 days following cyclone event. Another destitute woman informed that the situation was very worst; she could not think to take meal. Rahena illustrated "my sister and I passed the entire day collecting floated food and picking up fruits from in and around our house after the day of cyclone. Our family depends on this food for several days. In the BAA two or more households cooked together at that time, but it was really impossible to think at the normal period. The most of the survivors in BAA did not able to cook in households for at least five days following the recession of storm surge event. In this period, they took whatever food available to them such as wetted rice, bread, sweet potato, pumpkin, green banana, green coconut etc. Green coconut seemed to be only source of drinking water for several days following the cyclone event.

Following the devastating impact of the April 1991 tropical cyclone, the people of island became friendlier and extended all sort of cooperation to each other. The rich people took care of their poor neighbours and people living in the less affected area supplied meal to relatives living in the devastated zone. At this period, internal food-exchanges were occurred in large scale (Table 3). The people of BAA mostly received food help and the people of the rest two areas forwarded food help. In this process marital related relative's such as father-in-laws house, sister-in-laws house responses were very significant (Table 4). This also expressed in Kalama uttering: "I split up my family after cyclone. Wife along with two daughters and a son were sent at the house of the father-in-laws who resides in $M A A$ because I had no food to feed them. My wife sometimes visited me and my son who was living with me and brought food and other items for us. After 24 days of the cyclone event, she along with the other son and daughters 
Table 3. Household coping for food before arrival of relief. Source: [4], Number in parenthesis indicates percentage distribution.

\begin{tabular}{|c|c|c|c|}
\hline $\begin{array}{c}\text { Area } \\
\text { Sources }\end{array}$ & Badly Affected Area & $\begin{array}{c}\text { Moderately Affected } \\
\text { area }\end{array}$ & Less Affected Area \\
\hline Own family & $46(23)$ & $108(54)$ & $124(62)$ \\
\hline Relatives & $58(29)$ & $28(14)$ & $16(8)$ \\
\hline Local Market & $36(18)$ & $36(18)$ & $38(19)$ \\
\hline Picking up food & $44(22)$ & $22(11)$ & $6(3)$ \\
\hline Neighbour & $14(7)$ & $6(3)$ & $14(7)$ \\
\hline Other & $2(1)$ & - & $2(1)$ \\
\hline Total & $200(100)$ & $200(100)$ & $200(100)$ \\
\hline
\end{tabular}

Table 4. Household internal food-exchange after cyclone. Source: [3], Number in parenthesis indicates percentage distribution.

\begin{tabular}{|c|c|c|c|c|c|c|}
\hline $\begin{array}{c}\text { Area } \\
\text { Types }\end{array}$ & \multicolumn{2}{|c|}{ Badly Affected Area } & Moderately Affected area & \multicolumn{2}{c|}{ Less Affected Area } \\
\cline { 2 - 7 } & Receiving & Providing & Receiving & Providing & Receiving & Providing \\
\hline $\begin{array}{c}\text { Respondents } \\
\text { father-in-law's } \\
\text { house }\end{array}$ & $56(28)$ & 0 & $46(23)$ & $6(3)$ & $32(16)$ & $4(2)$ \\
\hline $\begin{array}{c}\text { Son's father-in- } \\
\text { laws house }\end{array}$ & $14(7)$ & 0 & $6(3)$ & $6(3)$ & $8(4)$ & $8(4)$ \\
\hline $\begin{array}{c}\text { Daughter's father- } \\
\text { in-law's house }\end{array}$ & $6(3)$ & 0 & 0 & $44(22)$ & 0 & $16(8)$ \\
\hline $\begin{array}{c}\text { Sister's father-in- } \\
\text { law's house }\end{array}$ & $14(7)$ & 0 & $14(7)$ & $18(9)$ & 0 & $28(14)$ \\
\hline Other relatives & $72(36)$ & $8(4)$ & $36(18)$ & $36(18)$ & $16(8)$ & $44(22)$ \\
\hline Neighbour & $26(13)$ & $4(2)$ & $14(7)$ & $20(10)$ & $16(8)$ & $24(12)$ \\
\hline Total & $188(94)$ & $12(6)$ & $92(46)$ & $106(53)$ & $72(36)$ & $126(63)$ \\
\hline
\end{tabular}

returned to our house permanently [3].

\section{Household coping for food during 1994/1995 droughts}

Droughts are a recurrent phenomenon in Bangladesh, afflicting the country at least as frequently as major floods and cyclones [26]. Since its independence in 1971, Bangladesh has suffered severe droughts in 1973, 1978, 1979, 1981, 1982, 1989, 1992, 1994 and 1995 ([2, 15], Erickson et al., 1993). In some years as in 1994 and 1995, drought was the lone environmental factor causing severe damage in the country [26]. In order to cope with the adverse effects of the 1994/1995 drought, those affected practised various adjustments at the household level. The affected local communities have, over the years, developed a range of long-and shortterm coping strategies. Paul (1998a) [26] suggested that only 8 per cent practised agricultural adjustments during the 1994/1995 drought period. The majority respondents did not practise adjustment due to lack of water. Households, who practised agricultural adjustments, cultivated more water-efficient crops such as kaon, jute, wheat and onion instead of rice. Paul (1998a) [26] also suggested that 88 percent of households had sold belongings to reduce their vulnerability to the 1994/1995 droughts. These were recorded as by selling their livestock (166 households), land (112 households) and by mortgaging their land (106 households). Only one member migrated to other area. Adoption of adjustments to drought at household level also significantly differs according to landholding size and tenancy status of the households. The small and medium farmers adopted adjustments than did farmers owning large landholdings.

\section{Household coping for food during 1996 Tangail tornadoes}

Unlike tropical cyclones, which usually affect the coastal areas of Bangladesh, tornado strike inland areas, particularly in the central part of the country [22, 30]. Paul (1998b) [27] studied about 1996-Tangail tornado which killed 700 villagers and caused extensive damage to foods, crops and livestock. Paul (1998b) [27] suggested that survival victims made no adjustment at the household level to cope with the devastating effects of the tornado. This contrasts with findings of previous hazard studies $[5,17$, $18,19,20,25]$. Two reasons were noted for not undertaking any household level adjustment strategies. Firstly, the survivors received disaster relief in cash and in kind immediately after the tornado event. Secondly there were acute shortages of labour. Alam (2005) [6] studied on Tornao-2003 in Brahmanbaria district which killed 22 persons and injured over 500. Alam (2005) [6] suggested that households adopted coping strategies to cope with tornado loss by selling properties and taking credits due to lack of rehabilitation programs from governmental Organisations (GO) and Non-Governmental Organisations (NGOs). 


\section{Discussions}

Several important points which require further elaboration and attention emerge from this research. It is noted that the GOs and NGOs have failed to recognize, detect slow onset disasters such as famine and drought in time. As casualties and human suffering in case of these disasters occur slowly but dangerously, the external agencies such as GOs and NGOs are found to response at a slow step. On the other hand, in case of rapid onset disasters such as flood, cyclone and tornado, GOs and NGOs are found to response quickly. In both cases, before external agencies intervention for the affected households, they have been found to adopt coping strategies. Some coping strategies are positive means of overcoming food shortages, for example off-farm employment when it is available, savings that can be called upon, community cooking by two or more household together, internal food exchange from badly affected areas to less or affected areas, from rich household to poor household, relative's responses specially marital relative households and so on. However, for many poor people coping strategies are negative - that is, they have a longterm detrimental effect. Examples of negative coping strategies are: severe reduction in food consumption, eating non-food items or low food value item, borrowing money, taking debt with high interest, selling productive assets, reducing expenditures on basic services such as health and education, a reduction in the number of consumers in the family sending to live and or work elsewhere. It was observed that a household adopt both positive and negative coping strategies simultaneously.

\section{Conclusions and Recommendations}

The research used secondary documents to understand household level coping strategies for food during and after disasters in Bangladesh. It reviews Sen's (1982) [29] entitlement approach in relation to understanding famine-1974 in Bangladesh where he shows that food security does not only depend on availability of food. The findings suggest that affected household themselves through their available resources, traditional social networks try to cope with disasters. These sort of coping strategies depend on types, severity and time of disaster and socio-demographic characteristics of the affected households. These findings of household coping in disasters of Bangladesh are also coincided with access model of Wisner et al., (2004) [38]. Generally poor and agricultural and fishing communities whose livelihood depends on hazardous locations are found to adopt least preferable coping strategies for food during and aftermath of disasters. The poor people have often used the least coping capacity to offset the hazard of disaster times [37] and are found to depend on external organizations help. Otherwise, they adopted forceful coping strategies for livelihood. These findings are also supported by Edgeworth and Collins (2006) [12] research on health care to diarrhoea where the affected households found to take forceful self care strategies in crisis period. It can be concluded without external help it is quite impossible to overcome food crisis in disasters in Bangladesh. Household food security is the most urgent factor of health security and also important element in building resilience to disasters. Household resilient for food security could be improved through better preparedness and household level capacity building programme before disasters to avoid nutritional risk after disaster.

\section{References}

[1]. Alamgir M, Arora P (1991) Providing Food Security for All, Intermediate Technology Publ, London, UK.

[2]. Adnan S (1993) Living with Floods: Lessons from the Drought of 1992. Research and Advisory Services, Dhaka.

[3]. Alam E (2002) Post Cyclone Adjustment Process: The Case of Sandwip, Bangladesh, MSc Thesis in the Department of Geography and Environment, University of Dhaka, Bangladesh, Unpublished.

[4]. Alam E (2003) Post cyclone adjustment processes: basic needs perspective. Oriental Geographer. 47(2): 47-60.

[5]. Alam E, Bhuiyan RH, Rahman MM (2004) Loss pattern of cyclone 1991: a study on Sandwip Island, Bangladesh. Chittagong Univ J Sci. 28 (2): 67-78.

[6]. Alam E (2005) Tornado Hazard in Bangladesh: Nature, Loss and Coping. Chittagong Univ J Sci. 29(1): 97-104.

[7]. Alam E, Collins AE (2010) Cyclone disaster vulnerability and response experiences in coastal Bangladesh. Disasters. 34(4): 931-954. Doi:10.1111/ j.0361-3666.2010.01176.x.

[8]. Alam E, Dominey-Howes D (2015) A new catalogue of tropical cyclones of the northern Bay of Bengal and the distribution and effects of selected landfalling events in Bangladesh: A new catalogue of tropical cyclones . Int J Climatol. 35 (6): 801-835. Doi: 10.1002/joc. 4035.

[9]. Biellik RJ, Henderson PL (1981) Mortality, Nutritional Status and Diet during the Famine in Karaomoja, Uganda, 1980. Lancet. 2(8259): 1330-3.

[10]. CRED (Centre for Research in the Epidemiology of Disasters) (2007) EMDAT: The OFDA/CRED International Disaster Data base- www.emdat.be Brussels : catholic University of Louvain.

[11]. Ninno CD, Dorosh PA, Smith LC (2003) Public Policy, Markets and Household Coping Strategies in Bangladesh: Avoiding a Food Security Crisis Following the 1998 Floods. World Dev. 31(7): 1221-1238.

[12]. Edgeworth R, Collins A (2006) Self-care as a response to diarrhoea in rural Bangladesh: Empowered choice or enforced adoption? Soc Sci Med. 63 (10): 2686-97.

[13]. Etienne G (1977) Bangladesh: Development in Perspective, Geneva: Graduate Institute of International Studies.

[14]. Erickson NJ, Ahmed QK, Chowdhury AR (1997) Socio-Economic Implications of Climate Change for Bangladesh. Bangladesh Unnayan Parishad, Dhaka. 1-45.

[15]. Hossain M (1990) Natural Calamities, instability in production and food policy in Bangladesh. The Bangladesh Development Studies. 18(1): 33-4.

[16]. Hewitt K (1997) Regions of Risk: A Geographical Introduction to Disasters, Harlow: Longman.

[17]. Haque CE (1993) Flood prevention and mitigation actions in Bangladesh: The "Sustainable Flood Plain Development" approach. Impact Assessment. $11(4)$ : 376-90.

[18]. Haque CE, Zaman M (1994) Vulnerability and Response to Riverine Hazards in Bangladesh: A Critique of Flood Control and Mitigation Processes. Disaster, Development and Environment. New York: John Wiley \& Sons.

[19]. Islam MA (1974) Tropical Cyclone: Coastal Bangladesh. Natural Hazards: Local, National, Global, Oxford University Press, London.

[20]. Khan AA (1974) Perception of Cyclone Hazard and Community Response in the Chittagong Coastal Area, Oriental Geographer. 18(2): 1.

[21]. Khan A (1999) The 1998 Bangladesh Floods and Food Security. In Natural Disasters and Policy Response in Asia: Implications for Food Security. Harvard University Asia Center, Cambridge.

[22]. Karim N (1995) Disasters in Bangladesh. Natural Hazards. 11(3): 247-58.

[23]. MoFDM (2007) Children art and essay competition .Comprehensive Disaster Management Programme. Ministry of Food and Disaster Management, Government of Bangladesh.

[24]. O"Donnell MR, Bacos D, Bennish ML (2002) Nutritional Response to the 1998 Bangladesh Flood Disaster: Sphere Minimum Standards in Disaster Response. Disasters. 26(3): 229-241.

[25]. Paul BK (1984) Perception of and agricultural adjustment to flood in Jamuna Floodplain, Bangladesh. Hum Eco. 12: 3-19.

[26]. Paul BK (1998a) Coping Mechanisms Practised by Drought Victims (1994/5) in North Bengal, Bangladesh, Appl Geogr. 18(4): 355-373.

[27]. Paul BK (1998b) Coping with the 1996 Tornado in Tangail, Bangladesh: An Analysis of Field Data. Prof Geogr. 50(3): 287-301.

[28]. Phillips DR (1990) Health and Health Care in the Third World. New York: Longman.

[29]. Sen A (1982) Poverty and Famines: An Essay on Entitlement and Deprivation, Oxford: Oxford University Press.

[30]. Schmidlin T, Ono Y (1996) Tornadoes in the District of Jamalpur and Tangail in Bangladesh. QR90. Boulder, CO: Natural Hazard Research and Applications Information Centre, University of Colorado.

[31]. Singleton RA, Straits BC (1999) Approaches to Social Research, the 3rd edi- 
tion. Oxford University Press, New York.

[32]. United Nations (1990) Policies to Improve Nutrition: What was done in the 1980s? SCS News No. 6. United Nations Administrative Committee on Coordination-subcommittee on Nutrition. Geneva. 12

[33]. United Nations (1948) The Universal Declaration of Human Rights. Geneva, Switzerland.

[34]. UNDP (2005) Human Development Report-2005. United Nations Development Programme: New York.

[35]. UNISDR (2016) United Nations International Strategy for Disaster Reduction, December 2016.

[36]. World Food Program (WFP) (1998) Food Security, Livelihoods and Food
Aid Interventions. A paper prepared by the Strategy and Policy Division of WFP, Rome, Italy.

[37]. Webb P, Harinarayan A (1999) A Measure of Uncertainty: The Nature of Vulnerability and it Relationship to Malnutrition. Disasters. 23(4): 292-305.

[38]. Wisner B, Blaikie P, Cannon T, Davis I (2004) At Risk: Natural hazards, people's vulnerability and disasters, 2nd (Edn), London and New York: Routledge.

[39]. World Bank (2005) Disaster Risk Management Series: Natural Disaster Hotspots: A Global Risk Analysis. Washington DC, U.S. 